\title{
Un Testimonio del Pensamiento Político Ilustrado Criollo: Manuel Moreno ${ }^{1}$
}

\author{
A Witness of the Creole Enlightned Political Thought: \\ Manuel Moreno
}

\section{Um Testemunho do Pensamento Ilustrado Crioulo: Manuel Moreno}

\author{
Celina A. Lértora Mendoza ${ }^{2}$ \\ Universidad Católica-Argentina \\ Grupo de investigación ILAC \\ fundacionfepai@yahoo.com.ar
}

Recepción: 10/09/2012

Evaluación: 04/07/2013

Aceptación: 15/05/2014

Artículo de Revisión

\section{RESUMEN}

La Ilustración criolla debe ser considerada en su relación con la Ilustración europea, pero con desarrollos propios y diferenciados según las regiones y las tradiciones locales. Este trabajo considera un solo rasgo consensuado como propio de la Ilustración: los principios políticos reformistas. Analizo un texto relevante de las ideas políticas que sustentaron quienes de hecho hicieron praxis políticas desde 1810 en adelante, para ver cuáles son los rasgos que pueden considerarse de tradición ilustrada, así como, al mismo tiempo, de qué manera los asumían aplicándolos a la situación que vivían: Vida y memorias del Dr. D. Mariano Moreno, de Manuel Moreno, su hermano, publicado en Londres, poco tiempo de la muerte del biografiado, en 1812. La propuesta que funciona como eje articulador de las ideas es la superación del despotismo ilustrado español. Las ideas centrales de carácter ilustrado que pueden rastrearse en este texto y que giran en torno a dicho eje son: 1) La participación ciudadana en la

1 Este trabajo es resultado del proyecto de investigación Discursos políticos de criollos ilustrados en las independencias americanas (código SGI: 1128), avalado por el Consejo Superior de Investigaciones Científicas (CSIC) y la Universidad Pedagógica y Tecnológica de Colombia (UPTC). Esta investigación fue desarrollada por el grupo Ilustración en América Colonial (ILAC), reconocido por Colciencias y adscrito a la Universidad Pedagógica y Tecnológica de Colombia.

2 Doctora en Filosofía por las Universidades Católica, Argentina, y Complutense de Madrid; investigadora del CONICET, en la Fundación para el Estudio del Pensamiento Argentino e Iberoamericano (FEPAI), M. T. de Alvear 1640, Buenos Aires, y del grupo Ilustración en América Colonial(ILAC, UPTC). 
cosa pública, 2) las equivocaciones políticas despóticas, 3) la libertad de comercio, 4) la legitimación de la insurrección, 5) la censura, 6) la enseñanza, 7) las profesiones liberales y 8) la formación del buen político. Termina con una apelación que preanuncia el pragmatismo criollo que guió, en mayor o menor medida, a los políticos más sagaces de la nueva generación. Se concluye que los rasgos analizados confirman la hipótesis.

Palabras clave: Revista Historia de la Educación Latinoamericana, Manuel Moreno, Mariano Moreno, ilustración rioplatense, reformismo político, despotismo ilustrado.

\section{ABSTRACT}

The Creole Enlightenment must be took into accout with its relation with the european enlightenment, but with suitable developments and differentiated according to the regions and the local traditions. This work has taken into account just one feature agreed as own of the enlightment: the political reformist principles. I analyze an outstanding text of the political ideas sustained by persons who did a political praxes since 1810 from now on, to see what are the features that can be considered as Enlightenment tradition and, at the same time how the situation they assumed by applying: life and memories of Dr. D. Mariano Moreno, Manuel Moreno, his brother, published in London, short time later the death of the biographer, in 1812. The proposal serves as a central axis of thel ideas of illustrated character that can be traced in this text and that turn concerning the above mentioned axis, are: 1 . The civil participation in the public thing; 2 . The political despotic mistakes; 3 . The freedom of commerce: 4. The legitimization of the insurrection; 5 . The censoring; 6 . The education; 7 . The liberal professions; 8 . The training of a good politician. It finished with the appeal that announced the creole pragmatism which guided to the most clever politicians of the new generation. It cocludes that the analized features prooved the hipothesis.
Key words: Journal History ofthe Latin american Educatio,Manuel Moreno - Mariano Moreno Enlightment from La Plata-Policy reformingEnlightment despotism.

\section{RESUMO}

A ilustração crioula deve ser considerada em sua relação com a ilustração europeia, porém com desenvolvimentos próprios e diferenciados, segundo as regiões e as tradições locais. Este trabalho considera somente um aspecto aceito como próprio da ilustração: os princípios políticos reformistas. Analiso um texto relevante das ideias políticas que sustentaram aqueles que de fato fizeram práxis política desde 1810 adiante, para ver quais são os aspectos que podem ser considerados de tradição ilustrada, assim como, ao mesmo tempo, de que maneira os assumiram aplicando-lhes ao contexto que viviam: vida e memórias do Dr. Mariano Moreno, de Manuel Moreno, seu irmão, publicado em Londres, pouco tempo depois da morte do biografado, em 1812. A proposta, que funciona como eixo articulador das ideias, e a superação do Despotismo ilustrado espanhol. As ideias centrais de caráter ilustrado que podem rastrear-se neste texto e que giram em torno ao referido eixo são: 1 . A participação cidadã na coisa pública; 2 . Os equívocos políticos despóticos; 3. A liberdade de comercio; 4. A legitimação da insurreição; 5 . A censura; 6. O ensino; 7. As profissões liberais; 8. A formação do bom político. Termina com um apelo que prenuncia o pragmatismo crioulo que guiou, em maior ou menor medida, os políticos mais sagazes da nova geração. Conclui-se que os aspectos analisados confirmam a hipótese.

Palavras-chave: Revista História da Educação Latino-americana, Manuel Moreno, Mariano Moreno, ilustração rioplatense, reformismo político, despotismo ilustrado. 


\section{INTRODUCCIÓN}

La Ilustración criolla debe ser considerada, sin duda, en su relación con la Ilustración europea, pero con desarrollos propios y diferenciados según las regiones y las tradiciones locales. ${ }^{3}$

Hay que señalar, como rasgos comunes: la asimilación del racionalismo, la exaltación de la utilidad de la ciencia, los principios reformistas en lo político, lo social, lo económico y la insistencia en la educación moderna, pero a la vez esto enlazado con la tradicional reivindicación de los nacidos en América frente a la metrópoli y la defensa tanto del pasado americano, como de los valores de la tierra americana, rasgos estos que los distinguen de los ilustrados europeos. ${ }^{4}$

Por lo que hace a la zona rioplatense, Diego Pró, siguiendo una tradición historiográfica bastante consolidada en Argentina, sostuvo que el Iluminismo entró en esta región por Manuel Belgrano, pero que los efectos se vieron recién en la generación siguiente. ${ }^{5} \mathrm{Al}$ contrario, Cristina Vera considera que muchos de los actores del proceso independentista, ya en años anteriores a 1810, tuvieron conocimiento de la Ilustración y admiraron sus ideas. ${ }^{6}$ Coincido con este criterio, porque advierto que, incluso en las aulas tradicionales, desde la última década del siglo XVIII se mencionan ideas ilustradas, aun cuando fuera para criticarlas y rechazarlas. De todos modos, para decidir si y en qué medida los agentes del 1810 fueron ilustrados es menester ponerse previamente de acuerdo en cuáles rasgos se considerarán ilustrados y luego analizar si los documentos pertinentes los exhiben.

Para este trabajo me reduciré a un solo rasgo que se admite pacíficamente como propio de la Ilustración: los principios políticos reformistas. Es claro que esta caracterización es aún insuficiente, puesto que los "reformadores" políticos son muy diferentes entre sí (piénsese en Locke, Voltaire, Didedot, D' Alembert, Rousseau, Montesquieu, etc.). No concuerdo con la tesis de algunos historiadores católicos, como Paul Hazard, 7 que ven en estas actitudes reformistas ante todo un ataque a la tradición católica, a la Iglesia Católica y al Papado. Creo que, sin duda, este sesgo anticlerical existe, pero me parece que es debido más bien a la política secular del Vaticano y de las jerarquías católicas dentro de las monarquías europeas alineándose con ellas, que a motivos estrictamente religiosos. De hecho, en mayor o menor medida y con más o menos sinceridad profunda, todos los gestores de la Gesta de Mayo se declaraban católicos y

3 Puede decirse que esta visión campea en la mayoría de las obras escritas en las dos últimas décadas del siglo XX, una selección de las cuales ha sido realizada por María Cristina Vera de Flachs, ed., "La ilustración: tradicionales y novedosas fuentes", en Universidad e Ilustración en América: nuevas Perspectivas (Córdoba, 2002), 159-195.

4 Diana Soto Arango, Miguel Ángel Puig Samper y María Dolores González-Ripoll, eds., Introducción a Científicos Criollos e Ilustración (Madrid: Doce Calles, Colciencias, RUDECOLOMBIA, 1999), 9.

5 Diego Pró, “Periodización y caracterización del pensamiento filosófico argentino", en Historia del pensamiento filosófico argentino (Mendoza: Universidad Nacional de Cuyo, Facultad de Filosofía y Letras, Instituto de Filosofía, 1973), 1: 143-184.

6 María Cristina Vera de Flachs, "Gregorio de Funes: un criollo ilustrado y la reforma del plan de estudios de la Universidad de Córdoba”, en Científicos Criollos e Ilustración (Madrid, Doce Calles, Colciencias, RUDECOLOMBIA, 1999), 136.

7 La desarrolla especialmente en dos obras: La crisis de la conciencia europea, trad. Julián Marías (Madrid: Pegaso, 1941) y Prólogo de El pensamiento europeo en el siglo XVIII, trad. Julián Marías (Madrid: Revista de Occidente, 1946), 2. Su tesis central es la esencia anticristiana de la Ilustración. En la segunda citada explica la Ilustración como un proceso de ruptura y negación del pasado, de toda religión y cultura que acepte la trascendencia para reemplazarla por una cultura racionalista e inmanentista. Un solo texto como ejemplo de esta interpretación: "Primero se alza un gran clamor crítico; los recién llegados reprochan a sus antecesores no haberles transmitido más que una sociedad mal hecha, toda de ilusiones y sufrimiento; un pasado secular sólo ha llevado a la desgracia; y ¿por qué? De este modo entablan públicamente un proceso de tal audacia, que sólo algunos hijos extraviados habían establecido oscuramente sus primeras piezas; pronto aparece el acusado: Cristo. El siglo XVIII no se contentó con una Reforma lo que quiso abatir es la Cruz; lo que quiso borrar es la idea de una comunicación de Dios con el hombre, de una revelación; lo que quiso destruir es una concepción religiosa de la vida". Obsérvese que las críticas mencionadas están efectivamente en los criollos ilustrados y el libro de Moreno es un ejemplo; pero ellos no sacan estas conclusiones que parecen más bien orientadas por una adhesión total y acrítica al cristianismo, sin considerar su realidad histórico-social 
contrarios a manifestaciones ateas o antirreligiosas de ciertos autores ilustrados. Esta fue una de las razones del rechazo bastante significativo a la obra de Rousseau.

Abandonando entonces la pretensión de elaborar un listado de adhesiones locales a la Ilustración que abarque a todos los pensadores así denominados, ${ }^{8}$ me propongo en cambio la vía de analizar algún texto relevante de las ideas políticas que sustentaron quienes de hecho hicieron praxis políticas desde 1810 en adelante y ver cuáles son los rasgos que pueden considerarse de tradición ilustrada, así como, al mismo tiempo, de qué manera los asumían y los "domesticaban", aplicándolos a la situación que vivían.

\section{Los hermanos Moreno y su lugar en la historia de la revolución rioplatense}

Me propongo entonces la figura de Manuel Moreno, por varias razones. En primer lugar, porque su actuación fue dilatada, lo que le dio la perspectiva necesaria para juzgar los hechos centrales. En segundo lugar, fue un testigo excepcional del primer choque ideológico producido con la creación del Gobierno Patrio y un defensor de su hermano Mariano, prematuramente desaparecido, pero cuyas ideas propició y difundió. En tercer lugar, porque además de ser un político ciertamente por imperio de las circunstancias (aunque tal vez tuviera cierta inclinación natural a ello), tuvo una amplia cultura y conocimientos científicos, vivió largos años fuera de América y pudo integrar visiones que, desde el teatro de los hechos políticos, eran menos claras. Y es precisamente en este aspecto, el de la cultura y la ciencia, donde su talante ilustrado se aprecia claramente. ${ }^{9}$

Sin embargo, considero que sus ideas políticas no pueden ser comprendidas sin referirlas, como si fueran un eco, a las de su hermano Mariano, verdadero adalid del pensamiento progresista rioplatense, sin duda más radical que el propio Belgrano. Esto mismo han constatado todos los historiadores que, siguiendo a su primer biógrafo, Juan María Gutiérrez, ${ }^{10}$ presentan a los dos hermanos casi como una unidad histórica. Y en efecto, hasta la muerte de Mariano siguieron sendas paralelas. Manuel nació en Buenos Aires, en 1781, dos años después que su hermano Mariano, siendo sus padres Manuel Moreno Argumosa y Ana María Valle, progenitores de una docena de hijos de los cuales, salvo de estos dos, casi nada se sabe. Ambos estudiaron en el Colegio de San Carlos y probablemente compartieron las críticas que Manuel pone en boca de Mariano sobre el carácter y nivel de su enseñanza.

Producida la revolución del 25 de mayo de 1810, Mariano es nombrado Secretario de la Junta que se instala en reemplazo del Virrey y al año siguiente es enviado como representante de la misma ante el gobierno británico, viaje en el que Manuel lo acompaña como secretario. Pero Mariano muere en el mar, antes de llegar a Londres, en marzo de 1812, y Manuel toma inmediatamente la iniciativa de defender a su hermano y hasta de acusar a Saavedra de su

8 Aunque los matices entre los historiadores son variados, hay un cierto consenso general en que nuestra Ilustración tuvo algunos caracteres distintivos determinados en buena medida por la propia tradición social. Así, por ejemplo, la obra de José Carlos Chiaramonte, Ensayo sobre la "Ilustración" argentina (Entre Ríos, Universidad Nacional del Litoral, 1962) y de Arturo A. Roig, La filosofía de las luces en la ciudad agrícola (Mendoza, Universidad Nacional de Cuyo, 1968) muestran que en las zonas del interior del virreinato el influjo ilustrado es concomitante al paso de la ciudad tradicional a la moderna, siendo esta última la que contiene en su seno una clase intelectual que suscribe ideas ilustradas (contrato social, ciudadanía, fisiocracia), pero con una peculiar conciencia histórica que le hace orientarse hacia el federalismo económico y jurídico y hacia el proteccionismo de las industrias locales, por lo cual no suscribe el pensamiento del libre comercio, propio de los ilustrados de Buenos Aires. Este es sólo un ejemplo de la complejidad del tema y muestra el peligro de trazar historias reduccionistas.

9 He tratado este aspecto en mi trabajo "Manuel Moreno y la naciente ciencia argentina”, en Científicos criollos e Ilustración (Madrid: Doce Calles, Colciencias, RUDECOLOMBIA, 1999), 151-167, cuya primera parte, semblanza de Manuel Moreno, reproduzco en lo esencial aquí.

10 Juan María Gutiérrez, "Noticias sobre la persona y vida pública del señor doctor don Manuel Moreno", Anales de la Universidad de Buenos Aires, vol. 2 (1877). 
muerte. ${ }^{11}$ Manuel tomó el cometido de explicitar las ideas de Mariano, que sin duda compartía, y lo hizo en un escrito biográfico bastante voluminoso titulado Vida y memorias del Dr. D. Mariano Moreno, Secretario de la Junta de Buenos Aires, capital de las Provincias del Río de la Plata, con una idea de su revolución y de la de México, Caracas, etc. Por su hermano D. Manuel Moreno, oficial de la Secretaría del mismo Gobierno de Buenos Aires, editado en Londres en 1812, traducido al inglés en 1813 y publicado en la revista Monthley Magazine, vol. 33. ${ }^{12}$

Moreno continuó en Inglaterra hasta 1815 en que regresó a Buenos Aires. Por diferencias políticas, se enemistó con el Director Supremo Pueyrredón, por lo que se exilió en Estados Unidos, donde estudió Medicina graduándose en la Universidad de Maryland. Allí participó en numerosas actividades científicas y culturales y se interesó por la Química. Llegó de regreso a Buenos Aires en 1821, fue electo diputado y mantuvo ese cargo, en elecciones sucesivas hasta 1826, pasando entonces a ser miembro del Congreso Constituyente. Pertenecía al Partido Federal, opuesto al Unitario del presidente Rivadavia, a cuya caída el gobierno de la Provincia de Buenos Aires, a cargo del Coronel Manuel Dorrego, le designó Ministro de Gobierno y Relaciones Exteriores, en el que tuvo una actuación accidentada, renunciando definitivamente en diciembre de 1827. Durante su estadía porteña, Manuel Moreno se dedicó, aunque un tanto esporádicamente, a la docencia de Química en la recién creada Universidad de Buenos Aires, con resultados poco satisfactorios, debidos a la fragilidad del proceso mismo, que he tenido ocasión de analizar en el trabajo ya mencionado. Sin embargo, vale decir aquí que la concepción de la ciencia que tenía Manuel es también propia de los ilustrados americanos, lo que Alberto Saladino García ha denominado "pragmatismo científico criollo". ${ }^{13}$

Luego de una segunda estadía en Londres como enviado extraordinario y Ministro Plenipotenciario, cargo que, habiendo sido otorgado por el Gobernador Manuel Dorrego, le fue retirado por su sucesor y enemigo político Juan Lavalle. Sin embargo, Manuel permaneció en Inglaterra y se dedicó a la selección y edición de documentos de su hermano Mariano, que se publicaron en Londres en 1836 con el título Colección de arengas en el foro y escritos del Dr. D. Mariano Moreno, abogado de Buenos Aries y secretario del primer gobierno en la revolución de aquel Estado. Mantuvo cargos diplomáticos en Estados Unidos y en Inglaterra durante el gobierno de Rosas, a cuya caída regresó a Buenos Aires, sin tener ya más participación política, hasta su muerte en 1857.

Las ideas políticas de Manuel Moreno, como he adelantado, pueden considerarse un eco y un desarrollo de las de su hermano, a las que sirvió de voz y pluma. En realidad, a diferencia de su hermano, Manuel Moreno no fue un político de acción por largo tiempo, sino durante un breve período (durante el gobierno de Dorrego); los cargos de representación diplomática sin duda estaban más acordes con su carácter, así como su estilo de recopilar documentación y

11 Las circunstancias de la muerte de Mariano, en efecto, son un poco extrañas, ya que -hasta donde ha podido reconstruirse el casohallándose descompuesto, el capitán le dio una medicina equivocada que le produjo la muerte. Como fue inmediatamente arrojado al mar, es poco lo que se pudo saber al respecto.

12 Se cita aquí por la edición de Buenos Aires, L. J. Rosso, 1937.

13 Cf. Alberto Saladino, Dos científicos de la Ilustración Hispanoamericana: J. A. Alzate y F. J. de Caldas (México, UNAM-UAEM, 1990), 9: “Casi todos los intelectuales de esa época imprimieron una orientación social a los conocimientos científicos. De esta forma, resulta explicable la gran cantidad de información que difundieron para enfrentar problemas de salud, alimenticios, técnicos, económicos, educativos, administrativos, culturales, etc. El pragmatismo en ciencia es una preocupación omnipresente en las investigaciones científicas del siglo XVIII.

La importancia que otorgaron, por otra parte, a la observación y experimentación comprueba que América Latina no ha vivido al margen de las corrientes científicas de la época. Al contrario, el permanente contacto con instituciones, científicos, libros y publicaciones europeos, en general, ratifica la principal fuente de influencia de la cultura latinoamericana. Por ello sostenemos que el significado de ciencia que aportaron los científicos latinoamericanos del período que estudiamos tienen profundas coincidencias con la idea moderna de ciencia gestada durante la Revolución Científica”. 
redactar los pasos necesarios para su comprensión histórica, poniendo en boca de un muerto célebre - su hermano - ideas que, sin duda, eran también suyas. He dicho, y ratifico, que a mi entender, la biografía de Mariano, así como la edición de sus escritos forenses y políticos, constituyeron para Manuel una especie de testamento político de ambos. ${ }^{14}$

\section{Ideas centrales de los hermanos Moreno}

En mi concepto, el rasgo más distintivo de los dos hermanos ${ }^{15}$ y de la Ilustración política rioplatense, en general, es la superación crítica del despotismo ilustrado español. Más aún, en esa misma línea, considero que los Moreno, así como otros integrantes del grupo revolucionario (Manuel Belgrano, Manuel de Sarratea, Juan José Castelli) consideraban muy negativamente al despotismo ilustrado español, incluso en los aspectos socioculturales, y de ahí su reformismo generalizado, que incluía una propuesta de un cambio radical en la concepción sociopolítica, es decir, el principio de la soberanía popular.

Sin embargo, la crítica al despotismo toma diversas variantes, ya que simultáneamente se atacan todas y cada una de las políticas "despóticas": en industria, comercio, educación, cultura. Es interesante observar, incluso, que cuando no se critica directamente a un gobierno, sino a un aliado - la Iglesia Católica-, la crítica a sus dogmas y procederes termina también siendo un alegato a favor de la libertad y contra la tiranía.

Repasaré entonces una serie de textos que abonan la hipótesis propuesta.

\section{Sobre la participación ciudadana en la cosa pública}

Una de las ideas ilustradas más recurrentes es la invocación al pueblo para que tome parte activa en la cosa pública, como contrapeso al oscurantismo despótico. La real superación del despotismo ilustrado sólo se logrará con el concurso aunado de todas las fuerzas vivas de una nación. En la opinión de Manuel Moreno, los regímenes despóticos han urdido hábiles estratagemas para evitarlo, de modo que los ciudadanos sólo toman conciencia política cuando algún hecho grave los sacude. Es el caso, para el Río de la Plata, de las invasiones inglesas de 1806 y 1807.

Mariano Moreno escribió una Memoria sobre la invasión inglesa de 1806, que su hermano glosa y transcribe parcialmente. ${ }^{16}$ Comentando la narración de la defensa popular de la ciudad de Buenos Aires, abandonada por el Virrey y por las tropas reales, afirma esa tesis: "Los

14 Lértora, "Manuel Moreno", 156.

15 Si bien, Mariano tuvo una participación más decisiva en los momentos cruciales del proceso independentista, es decir, en la Revolución del 25 de Mayo de 1810 y en su acción como Secretario de la Junta Gubernativa que se formó al deponer al Virrey, dada su muerte prematura, sus ideas políticas sólo pueden ser reconstruidas con unos pocos documentos de su pluma y con los testimonios de su hermano que, según reconocen en general los historiadores, eran compartidas por casi todos los jóvenes intelectuales; cf., por ejemplo, Carlos Egúes, Mariano Moreno y las ideas político-constitucionales de su época (Córdoba: Academia Nacional de Derecho y Ciencias Sociales de Córdoba, 2000).

16 En sus memorias, Moreno considera primeramente el estado político y comercial de la colonia, destacando la importancia del puerto de Buenos Aires, la cuestión del contrabando, y afirma que es el único puerto en América española que puede considerarse verdaderamente comercial; señala los errores políticos y tácticos del Virrey Sobremonte, que no solo tornaron inútiles las fuerzas militares que tenía para defender la ciudad sino que, al contrario, mandó a Montevideo a las tropas más veteranas, de modo que Buenos Aires quedó indefensa. Apunta también que se tomaron medidas absurdas de tal modo que, a la postre, sólo quedó el propio pueblo para defenderse. Critica al Cabildo por haber entregado el poder a Liniers que no había actuado heroica sino cobardemente. Mariano Moreno comenta algunos abusos de Liniers como Virrey, lo que pareciera una justificación por haberlo hecho fusilar acusado de conspirar contra la Junta de Mayo, acusación que su hermano Manuel intenta desestimar aduciendo graves razones de defensa pública. Manuel Moreno, Vida y memorias del Dr. D. Mariano Moreno (Buenos Aires: L. J. Rosso, 1937), 75 y ss. 
vecinos salieron, por la necesidad, del aislamiento en que una constitución calculada para tiempos tranquilos, o para contentar celos indiscretos, los había mantenido hasta entonces"17.

La defensa de la patria es un deber compartido por los gobernantes y el pueblo, forma parte de las cláusulas implícitas del pacto social y político; por lo tanto, si una de las partes lo incumple, la otra tiene no sólo el deber de cumplir por las dos, sino también el derecho de denunciar el pacto por incumplimiento. Veremos que esta es una de las ideas centrales esgrimidas en defensa de la legitimidad de la insurrección. ${ }^{18}$

\section{Sobre las equivocadas políticas despóticas}

Una de las principales acusaciones ilustradas a los gobiernos autocráticos es su ineptitud para mejorar el bien público del Estado. Como el despotismo sólo mira al bien particular de una élite, no se preocupa de pensar, realizar y afianzar políticas públicas de beneficio común a largo plazo, sino que busca una ganancia inmediata para sus fines particulares, casi siempre deletéreos y egoístas.

Escribiendo en 1812, y mirando el panorama de la economía española durante los tres siglos en que aprovechó los grandes recursos de sus colonias americanas, Manuel Moreno achaca a los gobiernos españoles un equivocado manejo de la riqueza del Estado.

Si la institución social del país mirase con el debido interés los que han trabajado en los cimientos de la prosperidad del Estado, que es la Agricultura, y si los Españoles no hubiesen aplicado su atención a las minas, con preferencia a los demás ramos que han de alimentar lo grueso del pueblo, los Indios no se verían abandonados a su indolencia, que más que de su carácter, es efecto / de la falta de estímulo y educación. ${ }^{19}$

El afán desmedido de explotación inmediata conduce a prácticas despóticas de carácter absolutamente inmoral e inhumano. Un ejemplo es el trabajo indígena en las minas:

Aunque la tiranía es poco celosa de excusar sus excesos, se ha querido disculpar esta práctica bárbara con el motivo de que sólo los naturales son bastante fuertes, por su temperamento, para resistir estos trabajos. Como los Españoles no han hecho hasta ahora la experiencia de sí mismos, puede muy bien sospecharse que es ésta una suposición arbitraria, inventada para cubrir su perfidia en / obligar a otros hombres como ellos a exponerse a peligros, que ellos no son capaces de arrostrar. ${ }^{20}$

Aunquelos criollos no se consideraban necesariamente como portavoces delas reivindicaciones indígenas que habían producido diversos levantamientos duramente sofocados, en los últimos

17 Manuel Moreno, Vida y memorias, 88.

18 Ideas análogas a las que expresa en el libro que comento, se reproducen en el artículo de Manuel Moreno, "Revolución en Buenos Aires", en Mayo, su filosofía, sus hechos, sus hombres (Buenos Aires. Concejo Deliberante a la Revolución de Mayo, 1960), 322: La idea central de este escrito es que la fidelidad a la Madre Patria no es un derecho absoluto de los monarcas, de modo que puedan obligar a sus Colonias a aceptar cualquier medida de gobierno. Se aprecia el pactismo subyacente: "Esta palabra fidelidad, no es en sí misma ningún derecho abstracto, que obliga a las Colonias a estar unidas materialmente y en todos eventos a su Metrópoli: no es otra cosa que la obligación que aquellas tienen de cumplir por su parte el contrato social que liga las partes a su Estado; pero siendo esta obligación mutua en todos los miembros que forman el Cuerpo Político, tan deber es de la Madre Patria ser fiel a sus Colonias, como éstas a ella. A buen seguro que la España no querrá entrar en el examen de quien ha sido el primero en faltar a pactos tan sagrados".

19 Moreno, Vida y memorias, 60-61.

20 Ibíd., 62-63. 
años de la colonia había un consenso generalizado contra la explotación de los naturales. Según narra Manuel, Mariano Moreno se dolía de esta situación de los indios en la zona de Bolivia y Perú.

[El conocimiento de nuevos excesos] ... le hacian frecuentemente unirse con los piadosos sentimientos de un virtuosos Prelado de la Paz, que tocado del espectáculo de estas desgracias e injusticia, solía decir en sus conversaciones, que pasaría gustoso el resto de su vida en los oscuros calabozos de los Moros, por no tener el triste desconsuelo de ver servir los Indios sin salario, y siempre / sujetos sin recurso al capricho de los opresores de su libertad y usurpadores de sus bienes. ${ }^{21}$

\section{La libertad de comercio}

Este era un punto de permanente fricción entre los criollos burgueses y las autoridades hispánicas. Fue también un tema espinoso para los anglófilos rioplatenses, pues precisamente los ingleses invadieron el territorio prometiendo lo que todos los criollos pedían: la libertad de comercio. Defenderla y al mismo tiempo condenar la invasión exigía un delicado equilibrio y notable sagacidad política, cualidades que - a juicio de su hermano Manuel- exhibe la memoria de Mariano Moreno, mostrando un modelo de cómo se debería proceder en las difíciles circunstancias presentes.

El modo de discutir si convenía el comercio libre con los ingleses en circunstancias tan extraordinarias; la refutación de los argumentos con que la oposición contrariaba la concesión; y la solidez de principios con que se trata la materia, dan tanto valor a este papel, como su estilo elevado, I y la valentía de sus demostraciones. Solo un escrito de esta clase podría haber arrancado del gobierno de una Colonia un permiso que las Leyes del País repugnaban; de un país que a más de las generales prohibiciones, era oprimido acaso más que otro alguno de la América del Sur por la triste condición de los Españoles Europeos que lo habitan. Una meditación ligera patentizará lo grande del triunfo, que la justicia y la razón consiguieron en la apertura del comercio. ${ }^{22}$

La última frase hace referencia, justamente, a las primeras medidas librecambistas que estaban tomando los gobiernos sublevados, cuyas consecuencias, naturalmente, en ese momento no se podían prever. Les resultaba incluso increíble la posición de las Cortes en España al respecto, como lo expresa Manuel Moreno, sin alcanzar el sentido pragmático de quienes esperaban salir de la crisis otra vez mediante el recurso a las casi inagotables riquezas americanas.

\section{La legitimación de la insurrección}

Un punto importante en la mirada política de los criollos ilustrados es que, como expresa Moreno, quienes carecen de la necesaria competencia política para ordenar bien un gobierno no pueden ser gobernantes. Es decir, en el fondo de la crítica a las medidas concretas, económicas y jurídicas, hay una implícita legitimación de la insurrección libertaria.

¿Por qué misterio los Gobiernos soberanos de España, nacidos en su Revolución, han conservado / el escandaloso sistema de restricciones de Comercio, $y$ han defendido, en circunstancias tan impropias, los mismos reglamentos que deshonraban la adminis-

21 Ibíd., 63

22 Ibíd., 96-97. 
tración de sus Reyes, contra cuyos vicios e ignorancia ellos mismos han declamado solemnemente? ¿Podrá ocultárseles que semejantes prohibiciones no sólo son injustas, impolíticas, y ruinosas, sino también mal calculadas para los intereses bien entendidos de la Madre patria? ${ }^{23}$

La crítica al monopolio comercial de la metrópoli, mostrando que es ruinoso para todos, es un tópico muy reiterado en los escritos americanos, tanto anteriores como inmediatamente posteriores a los movimientos revolucionarios. El nexo entre economía y política es tan inescindible, que el despotismo político determina el monopolio económico. Son como dos caras de una misma moneda y no se puede superar uno sin destruir el otro. En definitiva, los ilustrados rioplatenses, a menos de dos años de su accionar revolucionario contra un Virrey pero no, en principio, contra las Cortes que reemplazaban al rey, ya estaban convencidos de que ellas eran tan despóticas como el rey, al menos en lo relativo a sus dominios en América, y por lo tanto, América debía tomar el control de sus propios gobiernos.

Si a los que ejercen el poder supremo se ocultan verdades tan sabidas, no es justo que sigan un momento en los lugares que ocupan. Su ignorancia los hace indignos de gobernar la Nación. Acaso / estén ellos penetrados de la certeza de estos principios, y esperan ocasiones más oportunas para entablar las reformas. Yo apostaría que no hay nadie que pueda engañarse con pretexto tan impertinente. Si cuando la Metrópoli no tiene medios de seguir su comercio con sus posesiones transatlánticas, todavía no se alzan las viejas restricciones, podrá esperarse la enmienda cuando desahogada de las agonias en que se halla, tenga marina con que seguir su exclusivo intercurso? Mas es fuerza que las Colonias sufran contra derecho estas crueles vejaciones en beneficio de su Estado padre. ¿Lo oís, Americanos? Vosotros debéis resolver de una vez esa gran cuestión que hace tiempo agitáis en concreto. ${ }^{24}$

¿Cómo se legitima, desde un punto de vista ilustrado, la insurrección americana? Un argumento inmediato y específico acaba de exponerse. Pero, más en general, la idea es que sólo el pueblo puede legitimar a sus gobiernos: ${ }^{25}$ “Un Gobierno que está seguro de la rectitud de sus operaciones, que reconoce su estabilidad en el afecto de sus Súbditos, y que trata de corresponder sinceramente a la confianza pública, no huye jamás de que sus acciones sean examinadas". ${ }^{26}$

\section{La censura como expresión de despotismo}

Uno de los aspectos más molestos del autocratismo, para los intelectuales ilustrados, todos más o menos librepensadores, era la censura, sobre todo la censura previa. Aquí sí se puede hallar, sin mayores dificultades, un nexo inmediato entre despotismo y restricción del pensamiento y la expresión. Ahora bien, de hecho, la sociedad peninsular había soportado $-\mathrm{y}$ eventualmente aceptado- la censura a la imprenta y a la difusión de las ideas, mientras

\footnotetext{
23 Ibíd., 97-98.

24 Ibíd., 99-100.

25 Sobre este principio basa su repudio a la acción del Virrey Cisneros contra los insurrectos del Alto Perú (actual Bolivia) a quienes, sin haber escuchado ni juzgado imparcialmente, condenó a muerte, cometiendo un acto absolutamente ilegítimo, puesto que él ya no representaba a un gobierno central inexistente desde el momento de la cautividad del rey y habiéndose disuelto la Junta Central. En el artículo "Revolución en Buenos Aires”, Moreno lo plantea así: “¿Quién debería entretanto gobernar las Provincias de América a nombre del Cautivo Monarca? ¿Cuál era el derecho que tenía Cisneros para retener untando que en sí no era otra cosa que una delegación de la Junta Central ya extinguida, y que por lo tanto no podía ser legítimo sin recibir de nuevo ser de la voluntad del Pueblo?" (p. 329).

26 Moreno, Vida y memorias, 186
} 
que, por ejemplo, en Francia y en Inglaterra se la había combatido por todos los medios posibles. Pero, según el concepto de los criollos, América ya no es "España" (peninsular) en sentido total y absoluto, sino que, habiendo empezado por diferenciarse parcialmente, en ese momento (c. 1810) parece haber tomado una plena conciencia de su identidad nacional (es decir, de sus complejos orígenes y desarrollo) y haber llegado a una especie de "mayoría de edad".

La censura a la imprenta es, entonces, una consecuencia lógica del despotismo, concomitante con un régimen educativo oscurantista. Es una de las estrategias para evitar que circulen ideas contrarias al poder reinante y obstaculizar la formación de cuadros ciudadanos progresistas.

Del estado de opresión en que se hallaba Buenos Aires antes de su revolución, es fácil colegir las trabas que existían sobre la Imprenta. Ese garante único y poderoso de los derechos de los Pueblos, la libertad de escribir, estaba proscripta con los más terribles anatemas del Gobierno y la Religión. En toda la Monarquía Española el despotismo politico y sacerdotal habia encadenado las inquisiciones del entendimiento a ciertas máximas estrechas, que ni era lícito examinar ni desechar. El genio comprimido en esfera que le era permitido correr, perdía su vigor; y la curiosidad, desnuda de los estímulos que necesita para des/terrados. ${ }^{27}$

La idea de que América ya es distinta de España y que, a pesar de sus diferentes tradiciones internas, se trata de pueblos hermanos, le merece a Moreno un alegato de neto corte iluminista.

El honor de la Patria exigía también de mi que aprovechase la ocasión de preparar indirectamente la vindicación de mi Gobierno y de los demás de América que se reconocen por hermanos.

Sobre esta idea, me detendré un poco a considerar que las revoluciones de América no sólo han sido necesarias, sino también justas y legítimas. Lo primero resulta claramente del estado de verdadera disolución obrada en el Gobierno Nacional por la Invasión Francesa. En cuanto a lo segundo, si todavía se quiere que las Colonias / cerrasen los ojos a la urgencia del caso, y a todos los peligros que les amenazaban, sea permitido fijar ciertos principios, que constituyen la estabilidad de todos los Gobiernos y que, aunque bien sabidos, se afecta no obstante desconocer cuando se fundan intereses sobre la opresión de nuestros semejantes. Todo País que se halla bajo una constitución tiránica tiene derecho para romperla. Toda insurrección que se dirige a libertar una Provincia de la opresión, es legítima. Aquel Hombre es libre cuando goza de las clases de libertad que le corresponden en lo físico, en lo moral, en lo religioso, y en lo civil.

Un Estado es libre cuando es gobernado por la voluntad común de los Individuos que lo componen, y cuando cada Individuo regido por el Gobierno que hayan adoptado sus representantes, puede considerarse como legislador de símismo. Ahora: hay diferentes grados en la libertad de que es susceptible un Estado; pero no hay medio entre ser libre, o ser esclavo. Un Estado pequeño es capaz de mayor perfección en la exhibición de sus sufragios, que uno muy extenso, y será por tanto más libre; pero siempre se

27 Ibíd., 187-188. 
requiere que la voluntad de sus miembros material o virtualmente hayan formado la constitución, para no considerarlo tiranizado. ${ }^{28}$

La resonancia de ideas libertarias francesas es patente y no hace falta insistir en ello.

\section{La enseñanza oscurantista}

Una de las invectivas más fuertes y amargas que trasunta el escrito de Manuel Moreno va dirigida a la enseñanza que recibió en Buenos Aires. Hay que decir que su texto no es el único con sabor crítico que se produjo en ese tiempo, pero tal vez sí es uno de los más extensos y agresivos. Pero esta crítica debe entenderse, además, en relación con algunas ideas centrales del movimiento libertino que venía protestando, desde mediados del siglo XVII, sobre todo en Inglaterra y Francia, contra la excesiva ingerencia de los dogmas religiosos en el ámbito del pensamiento racional. Sin embargo, no creo que, en el caso de los criollos, esta coincidencia en el objetivo de reducir la acción religiosa a su propia esfera, es decir, la de los creyentes que voluntariamente aceptan sus directivas, implique una posición antirreligiosa y menos aún atea. En el caso de Manuel Moreno, me parece evidente que sus observaciones, además de ser ciertas, están guiadas por el deseo de organizar una educación pragmática y progresista, basada en la ciencia moderna y sus aplicaciones, en beneficio de toda la sociedad. Moreno conocía casos que le servían de parámetro comparativo, en cuanto a los resultados prácticos de la enseñanza.

Estoy muy lejos de recordar la propiedad y sabiduría que se advierte en el instituto de la Universidad de Oxford, o de Edimburgo, para demostrar comparativamente la pobreza de nuestra única fuente de instrucción pública, quedando el parangón más ligero con cualquier colegio de enseñanza en Europa, sería suficiente para que resultasen sus defectos. Baste decir, que aun los de España, que sin duda no es el país en que más se ha adelantado en / la materia, son todavia muy superiores al de Buenos Aires. En cuanto a la utilidad que debía esperarse de promover los conocimientos y las ciencias, estando reducidas sus lecciones a formar de los alumnos unos teólogos intolerantes, que gastan su tiempo en agitar y defender cuestiones abstractas sobre la divinidad, los ángeles, etc., y consumen su vida en averiguar las opiniones de autores antiguos que han establecido sistemas extravagantes y arbitrarios sobre puntos que nadie es capaz de conocer, debemos decir que es absolutamente ninguna. ${ }^{29}$

Sigue describiendo la inutilidad de una enseñanza que, a pesar de la buena voluntad de los profesores, es inútil porque carecen de la práctica científica adecuada para entender lo que enseñan. $Y$ concluye:

Este vergonzoso estado debe atribuirse en primer lugar al sistema de despotismo e ignorancia seguido constantemente por la corte de España en todos / sus dominios y principalmente en sus colonias, en segundo a la general posesión en que se han mantenido los eclesiásticos desde el tiempo de los monjes, de presidir a todo establecimiento literario. A pretexto de la presunción de virtud, que debían infundir en sus discípulos, los clérigos y frailes se han señoreado de todas las cátedras, y han cultivado con destreza este poderoso medio de aumentar su crédito y su poder. Sin embargo como sus

28 Ibíd.,153-154.

29 Ibíd., 28-29. 
miras principales son los asuntos de religión, no cuidan de instruirse en las ciencias naturales, y asi mal pueden comunicar a sus discípulos unos conocimientos que ellos no poseen. ${ }^{30}$

Es fácil ver que aquí se ataca frontalmente el acuerdo Trono y Altar, y si bien es verdad que el párrafo rezuma un sabor claramente anticlerical, yo no me atrevería a decir "antirreligioso", conforme lo expresado anteriormente. Hay otras interpretaciones y este es un punto en que las divergencias de los investigadores son notables, pero su discusión no corresponde aquí. ${ }^{31}$ El oscurantismo educativo como política despótica es aducido en otro caso en que Manuel Moreno difícilmente haya podido ser imparcial, dado que su propio hermano, así como Manuel Belgrano, todos ellos independentistas de la primera hora, estuvieron implicados: la fundación de la Escuela de Náutica y la Academia de dibujo y su posterior desguace por parte del gobierno central:

Por los años de 1796 se estableció en Buenos Aires una escuela de náutica, y una academia de dibujo y escultura, costeada por los fondos del consulado, un cuerpo meramente de comercio, erigido para promover los objetos del tráfico del país, juzgar las causas mercantiles, y fomentar la industria. En los tres años que corrieron hasta que se dio cuenta a la corte de Madrid de la erección de estas escuelas, pues el despotismo habia ordenado que toda distribución de fondos aun a cuerpos particulares estuviese sujeta a la inspección del ministerio, salieron excelentes Jóvenes que pudieron dirigir las embarcaciones a Europa, Lima, La Habana y otros puntos. Pero este adelantamiento provechoso a la colonia, y útil al fomento de sus artes e industria, no podía menos que disgustar a los que fundaban su interés en la ignorancia y abatimiento de sus naturales. La orden más furiosa fue expedida para abolir una institución que contrariaba su politica peculiar, y no solo fueron tan crueles nuestros tiranos que privaron a nuestra pobre juventud de este recurso, sino que tuvieron bastante imprudencia para insultar nuestra situación, asegurando que los conocimientos matemáticos, y el cultivo de las artes de gusto, no eran para la América. En los archivos del consulado existe esta bárbara disposición para monumento de nuestros agravios, y raro ejemplo de nuestro sufrimiento. ${ }^{32}$

Como contrapartida, Mariano Moreno, junto con otros patriotas, apenas producido el grito libertario se ocuparon de mejorar en lo posible la instrucción del pueblo, y lo hicieron en los primeros meses de gobierno de la Junta gubernativa, fundando dos instituciones de claro contenido práctico y democrático, es decir, destinadas al mejoramiento de la instrucción del pueblo y de sus funcionarios.

Ésta [la biblioteca] fue una de las ocupaciones más dulces que el Dr. Moreno tuvo en su vida. Como Hombre de Letras, veía complacer la plantación de un Establecimiento

30 Ibíd., 29-30.

31 Por otra parte, historiadores muy posteriores a Manuel Moreno han repetido su juicio, alegando los mismos documentos y hechos. Se trata de autores simpatizantes con el positivismo finisecular, entre los cuales merecen especial mención, por su trascendencia en la época, Juan Probst y Carlos Octavio Bunge. Probst, en La educación en la República Argentina durante la época colonia, 1771-1810, en Documentos para la Historia Argentina (Buenos Aires, 1924), afirma que, luego de la expulsión de los jesuitas, cuya enseñanza era exclusivamente escolástica, se introdujo la filosofía moderna, pese a lo cual su juicio en general es negativo (cf. pp. 36-41). Bunge, en el cap. VI de La evolución de la educación (Buenos Aires, 6a ed. 1920) sobre la Universidad de Córdoba, insiste en el marcado sesgo religioso de la enseñanza y en que las ideas y las leyes protegían las miras monopolísticas de la metrópoli, criticando el método memorístico de la enseñanza filosófica, que no era sino preparación a la teología "del más puro escolasticismo" (178).

32 Moreno, Vida y memorias, 30-31 
dirigido a extenderlas entre sus Compatriotas, y cada paso que se daba en la preparación del Edificio destinado a este objeto, se le representaba como una victoria conseguida sobre la ignorancia ... / Si la vuelta del despotismo metropolitano, que en mi opinión no es ya de temer, no viene a destruir este asilo de las luces del País, es de presumir que algún día se levantará en él la estatua de su fundador, como la que por igual motivo se votó a Benjamín Franklin.

Con el mismo empeño se estableció la Academia de matemáticas para la educación militar de nuestros Jóvenes Oficiales, cuya apertura se hizo solemnemente el 12 de Septiembre de 1810. Desde entonces es que la patria puede contar sobre el valor de sus defensores, que desnudos de los socorros de la ciencia, como hasta allí habian estado, no le prometían más que un apoyo incierto. Los militares de Buenos Aires recibirán la instrucción que ha formado los Escipiones, los Césares, los Turenas, los Santa Cruces, y otra infinidad de guerreros que han brillado en las edades pasadas y las presentes; $y$ su ilustre carrera se ensanchará a medida de los objetos que sean capaces de ejecutar, si su dedicación al estudio corresponde a las facilidades que les proporcionan a este Establecimiento el celo del Gobierno. Para obligar su aplicación, la Junta decretó que no serían promovidos los Oficiales que no hubiesen cursado competentemente la Academia. ${ }^{33}$

\section{Las profesiones liberales como reaseguro contra el despotismo}

Mientras que el acuerdo Trono-Altar privilegiaba, como es natural, las profesiones militares y clericales, los ilustrados en general tenían preferencia por las profesiones liberales y las tareas científicas propias de una clase burguesa en ascenso social y cada vez con mayores pretensiones políticas. Una arraigada y secular tradición hacía difícil a los hijos de burgueses enriquecidos llegar a altos lugares de la Iglesia o del Ejército, salvo que adquirieran un título de nobleza (pagándolo, o por matrimonio con alguna hija de nobles empobrecidos); en cambio, las profesiones liberales y las ciencias son "democráticas", en el preciso sentido de que cualquiera que tenga determinadas aptitudes objetivas puede aspirar a ellas y lograr, en consecuencia, el correspondiente reconocimiento social.

Manuel Moreno defiende la profesión del abogado, y seguramente no sólo porque su homenajeado hermano lo era, sino porque en realidad lo eran casi todos los "patriotas" y especialmente los que se habían formado en la Universidad de Chuquisaca, de donde provenía la mayoría de los juristas que integraron los primeros gobiernos patrios.

Pero el aprecio a la "noble profesión del abogado" no se limitaba al aspecto de su defensa de los derechos y libertades del ciudadano, sino que su mayor valor - casi una heroicidadresidía en oponerse a jueces prevaricadores y vendidos, cómplices del despotismo, y esto muchas veces les acarreaba grandes peligros y reales males.

El noble objeto de esta honorable profesión eleva el alma de los que la ejercitan, y aun en medio de los tiranos conservan siempre el decoro e independencia que los caracteriza. Puede decirse que en la Academia Española son los Abogados la parte más selecta de la sociedad, y los que mejor entienden su oficio. En ellos se encuentra más ilustración, y liberalidad de ideas que en ninguna otra de las clases del Estado; y sea dicho en honor de un Cuerpo benemérito, ellos han sido unos constantes y animosos defensores de la

33 Ibíd., 202-203. 
inocencia, y los únicos que no han doblado la rodilla al despotismo entronizado con el ejemplo de los Jueces prevaricadores a quienes rodeaban. ${ }^{34}$

La corrupción en las esferas que debieran ser de control y defensa del pueblo es una característica que la Ilustración siempre achacó a los regímenes despóticos. Manuel Moreno se hace eco, al recordar y alabar la sana y valiente conducta de su hermano Mariano, cuando ejercía su profesión de abogado.

Él mismo conocía que una conducta semejante [defensa de la justicia de la causa] ante unos Jueces corrompidos, no podía menos de ser peligrosa para su fortuna individual, pero a pesar de los propósitos de corregirse que hacía tranquilamente en su casa, trasladado al foro no se podía impedir de ser arrebatado de este santo entusiasmo y muchas veces los ministros de la arbitrariedad y la injusticia oyeron verdades de su boca, bien amargas, por cierto, pero que no podian contradecir. Es sin duda muy heroica la firmeza que un Magistrado debe ejercitar cuando sus decisiones están en oposición con los intereses o pasiones del poderoso, o las preocupaciones del pueblo, pero un funcionario público siempre tiene a su favor el crédito de su ministerio, y la influencia que le da su carácter; y no es / mucho valor correr algunos riesgos cuando se cuenta con alguna probabilidad de evitarlos. Un simple abogado sin consideración, sin riquezas, y sin más apoyo que la justicia que defiende, es verdaderamente un héroe, cuando se atreve a parecer ante un Tribunal ignorante, que no conoce otra regla en sus decreto que su antojo, y que tiene en sus manos en todo momento el poder terrible de arruinar al que haya tenido la osadía de analizar sus juicios, o manifestar sus errores con los colores propios. ${ }^{35}$

A modo de ejemplo, multiplicable ad libitum, narra un caso de arbitrariedad que defendió su hermano, en el cual el mismo juez, denunciado por un particular, se hacía cargo de la denuncia y, naturalmente, pretendía disolverla y acusar a su vez a la víctima. La característica oprobiosa de ser a la vez juez y parte era considerada como un caso típico de despotismo, que tendía a generalizarse en todos los estamentos favorecidos por el poder central en la medida que lo apoyaran.

Este despotismo era general en todas las audiencias de América, y además de la falta de libertad que de él / resultaba para ventilar los juicios, y la opresión de los que defienden los derechos del Ciudadano, sofocaba los talentos de los jurisconsultos, y los reducía a practicar meramente la rutina. ${ }^{36}$

\section{La formación del buen político}

Una idea cara a los ilustrados es la necesidad de una nueva educación que contrarreste la educación tradicional cómplice y coadyuvante del despotismo. Observa Moreno que los gobernantes despóticos tienen auxiliares y funcionarios de poco valor intelectual (además de ser, en general, de poco valor moral). Manuel menciona, en cambio, a su propio hermano como un modelo o ejemplo de cómo debe ser formado un joven si se aspira a que sea útil a la patria. Aunque nuestros intelectuales no se declaran rousseaunianos, es claro que conocen su obra y quizá también han logrado leerla accediendo a textos prohibidos que a veces conseguían

\footnotetext{
34 Ibíd.,55.

35 Ibíd.,58-59.

36 Ibíd.,59-60.
} 
por medio de parientes clérigos. La idea de una pedagogía libertaria está insertada desde los inicios del movimiento independentista rioplatense y el caso de la alabanza a la formación de Mariano Moreno es un ejemplo, y no sólo porque lo escriba su hermano.

Su [de su hermano] deseo de saber se extendía con igual empeño sobre todos los diferentes ramos que abraza la difícil ciencia de la legislación, y sus conocimientos se adelantaron a los varios ramos que aquella requiere para formar un hombre de Estado. Jamás se hubiera contentado con los medianos estudios de un Abogado ordinario, y un presentimiento de que algún día lo emplearía su Patria en grandes objetos, junto con una noble ambición de adquirir celebridad, le sugirió el cultivar con el mayor cuidado los departamentos de la elocuencia, politica, historia y geografía. ${ }^{37}$

Veamos, entonces, con más detalle, la observación sobre los conocimientos que debe tener un político. No basta con que conozca las leyes y los procedimientos judiciales al nivel medio en que lo hace un -incluso buen- abogado. Es decir, la formación política es específica en cuanto a su objeto, es multidisciplinaria, requiere saber elocuencia, política, historia, geografía. En otras palabras, debe estar formado para poder expresarse adecuadamente ante los ciudadanos, participar activamente en debates parlamentarios, en reuniones públicas, en escritos de difusión amplia. Pero esta formación literaria no ha de ser una retórica vacía, sino que debe estar anclada en conocimientos amplios y seguros. Obsérvese que el núcleo de disciplinas reclamadas no incluye a la filosofía ni a la teología, a las cuales ya ha criticado. La política, entendida como ciencia, es el conocimiento de los principios y estrategias para el correcto manejo de la cosa pública, tanto en lo legal y reglamentario, como en las medidas relativas a cada área, especialmente en producción de riquezas y comercio. La historia y la geografía son, para los ilustrados, dos disciplinas necesarias para el buen gobierno. La historia, en cuanto proporciona los datos sobre los cuales analizar y decidir medidas gubernamentales, a partir de una certera visión retro-prospectiva de la realidad. La geografía (que incluye el estudio del territorio y de la población) permite formar una idea clara de las fortalezas y debilidades de un Estado. Sin estos datos no es de esperar ninguna decisión atinada.

\section{Conclusiones de Manuel Moreno}

El escrito que comento, como se ha podido apreciar, no se limita a ser una biografía razonada y justificada de las acciones y del pensamiento de Mariano Moreno, sino que, mucho más allá de eso, permite a su hermano Manuel expresar un conjunto de ideas compartidas no sólo por ellos dos, sino en general por todo el grupo ilustrado de Buenos Aires, y que, desde luego, gozaba de consenso general entre los ilustrados americanos. Consciente de que debía dar un cierre teórico y a la vez programático, de sentido político, a la biografía de Mariano, adelanta al lector las conclusiones que él estima serán correctamente extraídas si el texto es leído con suficiente atención.

Aunque un poco extenso, es conveniente transcribirlo en su totalidad, y sin necesidad de mayores comentarios.

Si no me engaño, dos cosas pueden inferirse de este Escrito, leído con mediana atención: la primera, que la felicidad el País consiste en obtener su objeto, y no en volver sobre sus pasos. Un ligero cotejo entre la indole y efectos del Gobierno de España en sus Colonias, y los Gobiernos revolucionarios, es capaz de persuadir al

$37 \quad$ Ibíd., 56. 
observador imparcial, que si la América ha de ser feliz, es preciso que lo sea por medio de los últimos.

La segunda, que toda Nación que funde interesen las relaciones de comercio con aquellas partes del Mundo, debe desear la subsistencia de los nuevos Gobiernos; porque solo con ellos es que aquellos países pueden prosperar, y cuanto más ricos y opulentos tanta más utilidad presentarán a las empresas de otros Pueblos. Yo me espanto de ver que haya un Gobierno sabio que haya podido alucinarse sobre este punto tan claro. Los Españoles alegan ahora con una ostentación de triunfo, que la América está aniquilada, y sin fuerzas para asegurar la liberad que pretende: esto mismo es una razón para arrojarlos para siempre de un suelo, cuyas miserias han causado. ${ }^{38}$

Las revoluciones de América no tienen otro enemigo que los Gobiernos Españoles. Estos son los que con ofensa de la razón, y de los principios más obvios de la política, reclaman el auxilio de la humanidad a favor de la libertad en el Mundo antiguo, y abusan de este auxilio para afirmar su tiranía en el nuevo. ${ }^{39}$

Moreno manifiesta una gran admiración a los países más liberales de Europa, especialmente Inglaterra, con la cual afirma que deberían establecerse buenas relaciones comerciales en beneficio de todos. Pero, con realismo, observa que América no puede ni debe confiar sola y ciegamente en estas potencias ultramarinas, enredadas, a la postre, en sus propios conflictos regionales. Hay un párrafo de advertencia que debería ser leído con atención, sobre todo hoy, cuando la globalización, que hace dos siglos era apenas incipiente, está mostrando toda una gama de consecuencias muy ambivalentes, por decir lo menos.

Al terminar, Manuel Moreno formula una reflexión realista sobre las relaciones de Europa con las colonias americanas de España, que incluye no sólo una advertencia, sino también una idea programática que no siempre -lamentablemente- fue escuchada por los sucesivos gobiernos criollos.

No obstante todo esto [los apoyos, la conveniencia de comerciar, etc.] la opresión de las Colonias Españolas ha sido un asunto constante de declamación para la Europa, pero en el momento que ellas han querido levantarse de suestazo abatido, los intereses de la Europa se han combinado para hacer perpetuas sus miserias. Acaso tendrá la América Española que luchar contra las intrigas, la ignorancia, y la indiferencia, otro tanto que contra sus antiguos tiranos. En este caso la obra de su libertad será solo el fruto de la constancia de sus hijos - con sola ésta serán vencidos unos obstáculos formidables en su apariencia.

De este modo los pasos de la regeneración del País serán seguros, aunque más tardios. ;Cuántos Estados, huyendo de la esclavitud, han caído en cadenas forjadas por sus nuevos Amigos! La protección de cualquier Potencia de Europa no puede adquirirse en el día sin grandes sacrificios. Los Americanos del Sur, luego que hayan tocado por si solos el término de sus actuales trabajos, podrán decir con arrogancia digna de Hombres independientes, la felicidad de que gozamos no la debemos sino a

38 Ibíd., 243.

39 Ibíd., 245. 
nosotros mismos: ninguna Nación podrá pretender nuestra amistad sin haberla antes merecido. ${ }^{40}$

La obra se cierra, curiosamente, con una apelación que va más allá de la tradicional crítica ilustrada a los gobiernos despóticos europeos y preanuncia el pragmatismo criollo que guió, en mayor o menor medida, a los políticos más sagaces de la nueva generación.

\section{CONCLUSIÓN}

El análisis del pensamiento de Manuel Moreno, al hilo de la evocación de la figura de su hermano fallecido, muestra en primer lugar la presencia de elementos cosmovisionales, teóricos y propuestas de praxis política propias del pensamiento ilustrado en su versión criolla y situada primeramente en la zona inmediata de interés (el virreinato del Río de la Plata) y, por extensión, en el resto de la América española que se visualiza como una unidad histórica (además de geográfica y social) que exige una mirada política de conjunto.

En segundo lugar, tanto el hecho de exponer esas ideas como esencialmente compartidas por su hermano, y a través de él, de la generación que inició el movimiento de insurrección frente a la corona española, indica la existencia de un grupo, si bien pequeño en número, notablemente consolidado, comprometido en la difusión y la aplicación de las ideas ilustradas en los primeros tiempos revolucionarios.

Estas dos conclusiones no niegan la coexistencia de otros modelos de pensamiento, más tradicionales, cuyas fuentes podrían rastrearse a partir de la segunda mitad del siglo XVIII y que, sin duda, determinaron quiebres posteriores en la dinámica política de los gobiernos criollos subsiguientes. Al contrario, se trata de dar una hipótesis explicativa coherente al hecho cierto de la existencia, apenas tres lustros después, de graves escisiones en la intelectualidad criolla. El caso mismo de Manuel Moreno, funcionario del Gobernador Juan Manuel de Rosas, a quien ningún historiador considera pro-ilustrado ni mucho menos, muestra un panorama complejo y matizado de adhesiones que no necesariamente deban referirse al pragmatismo político. Esta constatación invita a ampliar e iluminar la mirada histórica para que pueda percibir los múltiples escorzos que la tradición historiográfica a veces ha oscurecido.

\section{REFERENCIAS}

Bunge, Carlos Octavio. La evolución de la educación. 6a ed. Buenos Aires: Vaccaro, 1920.

Chiaramonte, José Carlos. Ensayo sobre la "Ilustración" argentina. Entre Ríos: Universidad Nacional del Litoral, 1962.

Egúes, Carlos. Mariano Moreno y las ideas político-constitucionales de su época. Córdoba: Academia Nacional de Derecho y Ciencias Sociales de Córdoba, 2000.

Gutiérrez, Juan María. “Noticias sobre la persona y vida pública del señor doctor don Manuel Moreno", Anales de la Universidad de Buenos Aires vol. 2 (1877).

Hazard, Paul. La crisis de la conciencia europea, trad. Julián Marías. Madrid: Pegaso, 1941.

Hazard, Paul. Prólogo de El pensamiento europeo en el siglo XVIII, trad. Julián Marías, Ma-

$40 \quad$ Ibíd., 249. 
drid: Revista de Occidente, 1946.

Lértora Mendoza, Celina A. "Manuel Moreno y la naciente ciencia argentina", en Científicos criollos e Ilustración. Madrid: Doce Calles, Colciencias, RUDECOLOMBIA, 1999.

Moreno, Manuel. "Revolución en Buenos Aires", en Mayo, su filosofía, sus hechos, sus hombres, 322-331. Buenos Aires: Concejo Deliberante a la Revolución de Mayo, 1960:.

Moreno, Manuel. Vida y memorias del Doctor D. Mariano Moreno. Buenos Aires: L. J. Rosso, 1937.

Pró, Diego F. "Periodización y caracterización del pensamiento filosófico argentino". En Historia del pensamiento filosófico argentino, vol. 1. Mendoza: Universidad Nacional de Cuyo, Facultad de Filosofía y Letras, Instituto de Filosofía, 1973.

Probst, Juan. "La educación en la República Argentina durante la época colonial, 17711810", en Documentos para la Historia Argentina. Buenos Aires: 1924.

Roig, Arturo A. La filosofía de las luces en la ciudad agrícola. Mendoza: Universidad Nacional de Cuyo, 1968.

Saladino García, Alberto. Dos cientificos de la Ilustración Hispanoamericana: J. A. Alzate y F. J. de Caldas. México: UNAM-UAEM, 1990.

Soto Arango, Diana, Miguel Ángel Puig Samper y María Dolores González-Ripoll, eds. Introducción a Científicos criollos e Ilustración. Madrid: Doce Calles, Colciencias, RUDECOLOMBIA, 1999.

Vera de Flachs, María Cristina. "Gregorio de Funes: un criollo ilustrado y la reforma del plan de estudios de la Universidad de Córdoba". En Científicos criollos e Ilustración. Madrid: Doce Calles, Colciencias, RUDECOLOMBIA, 1999.

Vera de Flachs, María Cristina. "La ilustración: tradicionales y novedosas fuentes", en Universidad e Ilustración en América: nuevas Perspectivas, ed. María Cristina Vera de Flachs, Córdoba: 2002.

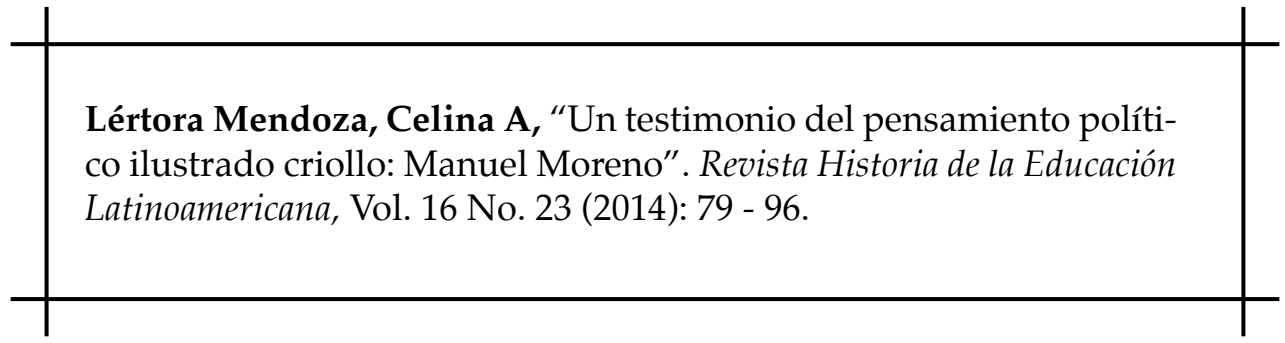

